\title{
BASES CONCEPTUALES PARA UNA DOCTRINA DEL SECRETO PROFESIONAL DEL ABOGADO EN CHILE
}

\author{
CONCEPTUAL FOUNDATIONS FOR A DOCTRINE OF THE \\ ATTORNEY-CLIENT PRIVILEGE IN CHILE
}

\author{
Álivaro Anríquez Novo** \\ ERnesto Vargas WeiL ${ }^{*}$
}

\begin{abstract}
RESUMEN: Este trabajo propone bases conceptuales para caracterizar dogmáticamente el secreto profesional del abogado. Argumenta que este es parte de un arreglo institucional mayor que busca permitirle al abogado acceder fluidamente a los hechos respecto de los cuales sus servicios son requeridos. Para entender cómo funciona ese entramado normativo es necesario distinguir el secreto profesional del deber de confidencialidad del abogado, por la vía de considerar al primero como una inmunidad procedimental que hace operativo el segundo frente a un requerimiento de información por el Estado. En la medida en que la inmunidad colisiona con el interés del Estado por acceder a los hechos necesarios para el ejercicio de jurisdicción, su ámbito de aplicación debe ser menor al del deber de confidencialidad.
\end{abstract}

Palabras clave: Secreto profesional; deber de confidencialidad; profesión jurídica.

ABSTRACT: This essay proposes theoretical foundations for characterizing the client-attorney privilege in Chile. It holds that the privilege is part of a wider institutional arrangement aiming to enable lawyers to fluently access the facts regarding which their services are engaged. Understanding this normative web requires to distinguish the client-attorney privilege from the lawyer's confidentiality duty, by considering the former as a procedural immunity that enables lawyers to comply with the latter when the State demands them to provide information. Insofar as the privilege collides with the interest of the State to access information for law enforcement purposes, its scope must be narrower than that of the confidentiality duty.

Keywords: Attorney client privilege; duty of confidentiality; legal profession.

\footnotetext{
* Abogado. Licenciado en Ciencias Jurídicas y Sociales, Universidad de Chile; Master of Comparative Jurisprudence, New York University. Profesor Asistente, Departamento de Ciencias del Derecho, Universidad de Chile. Dirección postal: Avda. Apoquindo 4775, oficina 1001, Las Condes, Santiago de Chile. Correo electrónico: aanriquez@q-an.cl. Código Orcid: 0000-0001-5281-4231.

** Abogado. Licenciado en Ciencias Jurídicas y Sociales, Universidad de Chile; Master en Políticas Públicas, Universidad de Chile; Master of Laws, New York University. Estudiante de Doctorado, University College London. Profesor Asistente, Departamento de Derecho Privado, Universidad de Chile. Dirección postal: Avda. Apoquindo 4775, oficina 1001, Las Condes, Santiago de Chile. Correo electrónico: ernesto.vargas@derecho. uchile.cl. Código Orcid: 0000-0001-7726-5224.

Los autores agradecen a Michelle Rencoret Lioi y Pablo Fuenzalida Cifuentes por sus comentarios y ayuda en la redacción de un primer borrador de este trabajo. Los errores son responsabilidad de los autores.
} 


\section{INTRODUCCIÓN}

La creciente invocación del secreto profesional del abogado ("Secreto Profesional)"1 en la práctica judicial de los Estados Unidos de América (“EE.UU.”), así como la sofisticación necesaria para aplicarlo en el contexto de una sociedad moderna ${ }^{2}$, han impulsado un intenso desarrollo dogmático del mismo en dicho país, especialmente en lo que dice relación con su preponderancia y límites. Si bien en Chile las mismas razones han generado un incipiente interés en esta institución ${ }^{3}$, su entendimiento sigue siendo insuficiente ${ }^{4}$, haciendo urgente una mayor elaboración.

Considerando lo anterior, el presente artículo se sirve de la experiencia comparada para identificar la justificación normativa y elaborar los presupuestos doctrinarios requeridos para una adecuada aplicación del Secreto Profesional en Chile. En particular, sostiene que una dogmática del Secreto Profesional en Chile debe partir por distinguir dicha institución del Deber de Confidencialidad. Este último abarca toda la información sobre el cliente y el asunto objeto de consulta que el abogado ha conocido en su desempeño profesional. En cambio, el Secreto Profesional es una inmunidad que hace operativo el Deber de Confidencialidad cuando el Estado requiere al abogado información en el contexto de un proceso jurisdiccional o administrativo. Por lo tanto, el deber de confidencialidad del abogado ("Deber de Confidencialidad"). es un presupuesto del Secreto Profesional.

El artículo está estructurado de la siguiente manera: En primer lugar, describe la importancia del Secreto Profesional para la profesión jurídica y el Derecho en general. A continuación, distingue el Secreto Profesional del Deber de Confidencialidad, entendiendo a este último como un presupuesto del primero. En tercer lugar, caracteriza al Secreto Profesional como una inmunidad que permite hacer operativo el Deber de Confidencialidad frente a un requerimiento de información por el Estado. Luego, identifica las razones que justifican la procedencia de esta inmunidad y cómo ellas determinan sus límites. En quinto lugar, damos cuenta del estado actual de jurisprudencia y doctrina sobre el Secreto Profesional en Chile. El trabajo finaliza con unas breves conclusiones.

\footnotetext{
1 "Hoy en día [2007] difícilmente hay un caso litigado, al menos en las cortes federales [de EE.UU.,] donde el problema del Privilegio [Cliente-Abogado] [no] recurra repetidamente, requiriendo invertir incontables cantidades de recursos de abogados para revisar [la presencia de] Privilegios y tiempo de los tribunales para determinar si afirmaciones sobre Privilegio y protección del Producto del Trabajo son correctamente planteadas", EPSTEIN (2007) p. xxiii.

2 En la actualidad, la abogacía tradicional coexiste con otra en que los clientes son organizaciones complejas; los servicios jurídicos son prestados por equipos jerarquizados de abogados dentro o fuera de la estructura corporativa del mismo cliente; las comunicaciones entre el cliente y abogados son transmitidas por medios que dejan registros (por ejemplo, correo electrónico) o pueden ser interceptados por la autoridad (por ejemplo, comunicaciones telefónicas), etc. Para una descripción del ejercicio profesional actual en Chile, ver De LA MazA (2002) pp. 203-204 y 209-2012, respectivamente; para los Estados Unidos, Posner (1994) pp. 60-70.

3 El ejemplo más claro de ello es la regulación al respecto en el Código de Ética Profesional de 2011 del Colegio de Abogados de Chile A.G. (“CEP 2011”), ver sección III de este trabajo.

4 Ver sección VI de este trabajo.
} 


\section{ROL DEL ABOGADO, DEBER DE CONFIDENCIALIDADY SECRETO PROFESIONAL}

En la medida en que las regulaciones sociales se formalizan y dejan de ser costumbres seguidas por la comunidad en forma espontánea, se suscita la necesidad de promover su cumplimiento. Con ese fin, surgen tres instituciones, dedicadas respectivamente a (i) la resolución de disputas por medio de terceros imparciales (mediación y adjudicación), (ii) hacer cumplir las regulaciones (policía) y (iii) custodiar el conocimiento y la experiencia sobre las regulaciones y, especialmente, su aplicación en el proceso de resolución de disputas (consejo). En Sociología del Derecho existe fuerte evidencia de que el "consejo" es el último de estos tres elementos en tomar forma, ya que contar con una clase de expertos en las regulaciones (esto es, abogados) solo se vuelve necesario cuando estas han alcanzado un nivel de sofisticación tal que son de difícil acceso para el lego y requieren ser explicadas y sistematizadas en la forma de doctrina ${ }^{5}$. De esta forma, los abogados cumplen la crucial función de mediar entre el caso concreto de su cliente y las normas que emanan de las fórmulas generales de ley o de la casuística de una línea de precedentes. Para cumplir esa función en forma satisfactoria, el abogado necesita acceder a los hechos del caso, los que muy generalmente le son informados (íntegra o, al menos, germinalmente) por el cliente. El Deber de Confidencialidad y el Secreto Profesional tienen por principal finalidad el hacer ese acceso posible y, ojalá, fluido.

La retórica de la práctica profesional suele enfatizar que, al ejercer ese rol mediador entre hechos y normas, los abogados ponen su compromiso con el cliente y con el Derecho por sobre cualquier otra consideración ${ }^{6}$. Sin embargo, el compromiso simultáneo con ambos intereses puede poner al abogado en una contradicción ${ }^{7}$. La regulación del Deber de Confidencialidad y del Secreto Profesional juegan un rol central en resolver esa tensión, siendo un reflejo de cómo una determinada sociedad entiende el Derecho y, especialmente, la función del abogado. Sociedades que tienden a ver el Derecho como instrumento para el cambio social deliberado suelen asignar al abogado un rol fuertemente comprometido con el aparato público de Justicia y relativamente desvinculado del interés del cliente. Este es el ideal de la profesión como "servicio público", generalmente asociado a un Deber de Confidencialidad y Secreto Profesional relativamente débiles. El problema de un Deber de Confidencialidad y Secreto Profesional de baja intensidad es que, en el extremo, expone al cliente al riesgo de que su abogado revele información que quiere mantener confidencial, por lo que tiende a inhibir la consulta, comprometiendo así el éxito de la labor mediado-

\footnotetext{
5 Ver Cotterell (1992) pp. 179-180.

6 Cotterell (1992) p. 187.

7 Sobre la profundidad que puede alcanzar esa contradicción ver Blumberg (1967) pp. 20-24. En Chile, los artículos $1^{\circ}$ y 25 del Código de Ética Profesional del Colegio de Abogados de Chile de 1948 ("CEP 1948”), así como el artículo 520 del Código Orgánico de Tribunales, no advierten el carácter problemático de esta exigencia dicotómica. Sobre la forma en como el derecho y la cultura jurídica chilena ven el rol del abogado en el enfrentamiento entre el interés del cliente y los valores del ordenamiento jurídico, ver SQueLLa (2001) pp. 573577.

8 Cotterell (1992) pp. 87-88.
} 
ra del abogado. Esas consecuencias son socialmente graves respecto de los casos difíciles, esto es, aquéllos que permiten más de una respuesta plausible a la luz de los criterios de plausibilidad del sistema jurídico de que se trate y que corresponden a la mayoría de los casos que se acumulan en los escritorios de los abogados (sus servicios son demasiado caros para lo obvio).

En cambio, en tradiciones que entienden el Derecho primariamente como una técnica de protección del individuo frente al Estado, los abogados cumplen un rol mucho más funcional al interés de su cliente y relativamente indiferente con el aparato jurisdiccional, razón por la cual se les tiende a vincular con un Deber de Confidencialidad y Secreto Profesional relativamente intensos. El problema de este paradigma profesional es que, en el extremo, incentiva el uso del Deber de Confidencialidad y del Secreto Profesional para facilitar al cliente evadir el cumplimiento coactivo del Derecho por la vía de ocultar hechos al Estado.

\section{EL DEBER DE CONFIDENCIALIDAD COMO PRESUPUESTO DEL SECRETO PROFESIONAL}

En el contexto antes descrito, el Secreto Profesional funciona como una inmunidad ${ }^{9}$ que habilita al abogado para negarse lícitamente a entregar a una autoridad pública cierta información relacionada con los servicios que presta. La procedencia de esta inmunidad tiene un presupuesto de derecho privado. El Secreto Profesional solo aplica a informaciones que están, a su vez, cubiertas por el Deber de Confidencialidad ${ }^{10}$. De esta forma, el Secreto Profesional no tiene una existencia autónoma: solo hay Secreto Profesional respecto de información sujeta a Deber de Confidencialidad (aunque la presencia del segundo no asegura la presencia del primero). Por lo mismo, resulta necesario entender el Deber de Confidencialidad para desarrollar adecuadamente el Secreto Profesional. A diferencia de muchos de los países herederos de la tradición jurídica del Código de Napoleón ${ }^{11}$, esta relación entre Deber de Confidencialidad y Secreto Profesional, así como la mayor extensión del prime-

\footnotetext{
9 Usamos acá el término inmunidad en la forma que lo hace Hohfeld, esto es, como una relación jurídica que niega la existencia del poder de otro para imponerle a alguien una determinada carga. Ver Hohfeld (1913) p. 55.

10 La referencia a "Deber de Confidencialidad" en este trabajo es a aquél que pesa sobre el abogado en favor de su cliente y excluye, por consiguiente, el deber que "cubre (...) las confidencias de los colegas", a que se refiere el artículo 11 del CEP 1948 y los artículos 110 y 111 del CEP 2011.

11 "En la mayor parte de los países herederos del Código de Napoleón, el concepto de privilegio testimonial y el [deber de] confidencialidad es coextensivo”. Epstein (2007) p. 19.
} 
ro, son explícitamente reconocidas por el derecho de los EE.UU. ${ }^{12}$ y el derecho alemán ${ }^{13}$. En esta línea y a pesar de su histórica dependencia de la codificación francesa, el derecho chileno expresamente limita el Secreto Profesional a los hechos que se le hayan comunicado “confidencialmente" (Art. 360 No 1 Código de Procedimiento Civil, "CPC”) o bajo "obligación de guardar secreto" al abogado (Art. 303 Código Procesal penal, "CPP”), mientras que entiende el Deber de Confidencialidad en términos mucho más extensivos, según veremos a continuación. De lo anterior resulta que el Deber de Confidencialidad debe ser considerado como un presupuesto necesario, pero no suficiente para la procedencia del Secreto Profesional.

En términos generales, se puede definir el Deber de Confidencialidad como una obligación civil negativa de fuente contractual ${ }^{14}$, reconocida por la ley y la lex artis de la profesión ${ }^{15}$, de carácter fiduciario ${ }^{16}$, consistente esencialmente en el deber del abogado de guardar reserva sobre (abstenerse de divulgar) toda la información relativa a su cliente que ha adquirido en el ejercicio de su profesión. Dado su carácter de obligación civil y a que ha sido establecida en el interés directo de su acreedor (el cliente), el Deber de Confidencialidad es renunciable por este (Art. 12 Código Civil, “CC”). La naturaleza fiduciaria de la relación del abogado con su cliente exige al abogado cuyo cliente se propone renunciar al derecho correlativo del Deber de Confidencialidad, informar a ese cliente que no está obligado a hacerlo, así como de las consecuencias previsibles y plausibles de esa decisión.

Con la excepción del nuevo Código de Ética Profesional de 2011 del Colegio de Abogados de Chile A.G. ("CEP 2011"), el desarrollo de la institución del Deber de Confidencialidad (y, en especial, su diferenciación respecto del Secreto Profesional) ha sido his-

\footnotetext{
12 En el derecho de los EE.UU., el Deber de Confidencialidad se encuentra definido en términos mucho más extensivos que las informaciones cubiertas por el privilegio cliente abogado y la doctrina del producto del trabajo. Lo anterior es especialmente notorio respecto de los Estados de ese país que, en lo sustancial, han adoptado la Regla 1.6(a) de las American Bar Association Model Rules of Professional Conduct (por ejemplo, Illinois, Massachusets, Florida, Pennsylvania), pero también aplica a aquéllos que se apartan de esa regla y definen el Deber de Confidencialidad en forma algo más restringida (por ejemplo, California, Nueva York y el Distrito de Columbia). EPSTEIN (2007) pp. 15-16. Ver también regulación profesional de los Estados mencionados, accesible a través de la página web de la American Bar Association. El Derecho de Inglaterra, Escocia e Irlanda sigue líneas similares. Epstein (2007) p. 761.

13 En el derecho alemán, el Deber de Confidencialidad está establecido en la $\$$ 43a de la Bundesrechtsanwaltsordnung y es una institución diferente del "derecho del testigo a callar" (Zeugnisverweigerungsrecht), establecido en las $\$ \$ 383$ de la Zivilprozessordnung (ZPO) y 53 de la Strafprozessordnung (StPO).

${ }^{14}$ La naturaleza civil de esta obligación, esto es, si es imperativa o supletoria, no es una cuestión resuelta claramente y requiere una reflexión sobre las condiciones que deben cumplirse para que el cliente pueda renunciar al derecho correlativo al Deber de Confidencialidad, que escapa al objetivo del presente trabajo.

15 Los códigos de ética (en rigor, de buenas prácticas) profesionales son el primer lugar en donde buscar la lex artis de esa profesión (BARros (2006) pp. 103-104 y 663; Cabe destacar que el CEP 2011 (i) dota al Deber de Confidencialidad de una mayor extensión que el CEP 1948 y (ii) distingue con nitidez el nivel deontológico, que aborda vía regular el Deber de Confidencialidad, del nivel procesal, que se abstiene de abordar, limitándose a incluir como contenido normativo del Deber de Confidencialidad la exigencia al abogado de invocar el Secreto Profesional cuando sea conminado por autoridad judicial o administrativa a declarar o entregar información obtenida en el ejercicio profesional.

16 El artículo 2118 de nuestro Código Civil sujeta los servicios de las profesiones que requieren de largos estudios a las reglas del mandato. La abogacía es una de tales profesiones y el Deber de Confidencialidad, una obligación vinculada estructuralmente a la labor del abogado.
} 
tóricamente escaso en Chile. El CEP 2011 constituye un salto conceptual en esta materia, proveniente, en buena medida, de una reflexión crítica llevada al interior de ese colegio sobre el tratamiento de estas instituciones en los EE.UU. de América, país en que las instituciones del Deber de Confidencialidad y el Secreto Profesional cuentan con un rico y reciente desarrollo dogmático. Tanto la regulación sobre Deber de Confidencialidad propuesta por la Asociación de Colegios de Abogados de ese país (American Bar Association), que ha sido sustancialmente seguida por un número significativo de sus Estados, como el CEP 2011, conciben al Deber de Confidencialidad en términos extremadamente amplios, incluyendo toda la información que el abogado conoce con ocasión de la encomienda profesional, prácticamente sin discriminación ${ }^{17}$.

Normalmente, este entendimiento expansivo del Deber de Confidencialidad no es problemático ya que ese deber suele operar en contextos en que no existe otro interés o valor jurídico cautelado por el ordenamiento jurídico que se le oponga o lo tensione (esto es, que requiera se revele información). Sin embargo, existen escenarios en que el Deber de Confidencialidad entra en conflicto con otras instituciones del ordenamiento jurídico. El caso paradigmático es el enfrentamiento del Deber de Confidencialidad con la carga pública de revelar información en el marco de un proceso jurisdiccional, o controlado jurisdiccionalmente, típicamente, declarar como testigo, entregar documentos o soportar incautaciones. En principio, en estos casos, el abogado tendría que elegir: o revela la información recibida de su cliente e incumple su Deber de Confidencialidad para con él o guarda la información e incumple con la carga que le impone el Estado. Por regla general, el Derecho exigiría al abogado optar por la carga pública. La razón de ello es fácil de entender y no requiere entrar a juzgar la importancia relativa de los bienes jurídicos protegidos. Si el Derecho prefiriera sin más el Deber de Confidencialidad, las partes podrían, vía pacto, crear libremente inmunidades frente a las cargas públicas, lo que en la práctica equivaldría a una derogación convencional de una potestad legal: o sea, a concluir que la potestad no existe como tal.

\section{EL SECRETO PROFESIONAL COMO INMUNIDAD}

Con todo, en algunos casos, los principales ordenamientos jurídicos occidentales resuelven el conflicto entre la carga pública de entregar información y el Deber de Confidencialidad en favor de este último, permitiendo al abogado mantener en reserva la comunicación con el cliente a pesar del requerimiento de autoridad. En el Derecho inglés esta solución tiene una larga tradición que se remonta a un caso del siglo XVI ${ }^{18}$. El Derecho alemán reconoce a los abogados el "derecho del testigo a callar" (Zeugnisverweigerungsrecht), tanto en el proceso civil ( $\$ 383 \mathrm{ZPO})$ como en el penal ( $\$ 53 \mathrm{StPO})$. En el Derecho fran-

\footnotetext{
17 La Regla 1.6(a) de las American Bar Association Model Rules of Professional Conduct dispone: "Un abogado no revelará información relativa a la representación de un cliente" (traducción es nuestra). Por su parte, la última frase del Art. $7^{\circ}$ del CEP 2011 prescribe: "La confidencialidad debida se extiende a toda la información relativa a los asuntos del cliente que el abogado ha conocido en el ejercicio de su profesión, [...]”. La consagración del Deber de Confidencialidad en el derecho alemán es igualmente amplia (ver \$43a(2) Bundesrechtsanwaltsordnung).

18 BERD V LOVELACE (1577).
} 
cés, por ejemplo, en el contexto de la incautación, se establece, inter alia, el deber para la policía judicial, en forma previa al examen de documentos a ser incautados, de tomar cualquier paso que resulte apropiado para asegurar la observancia del Secreto Profesional (Arts. 56 (3) Code de Procédure Pénale, “C. Pr. Pén.”) y solo permite la inspección e incautación de objetos del despacho del abogado cuando los realiza un juez o fiscal y en la presencia del presidente del colegio de abogados o la persona que este delegue al efecto (art. 56-1 (1) y (2) C. Pr. Pén).

Debido al rol que el procedimiento y el abogado han tenido históricamente en el desarrollo del common law ${ }^{19}$, esta es probablemente la tradición que cuenta con el tratamiento más sofisticado de este problema. En los EE.UU., el derecho soluciona el conflicto entre carga pública y Deber de Confidencialidad por la vía de reconocer inmunidades para ciertas comunicaciones entre el cliente y su abogado (el "Privilegio Cliente-Abogado" ${ }^{20}$ ), así como para parte del trabajo que el abogado ha realizado para su cliente (la llamada "Doctrina del Producto del Trabajo" ${ }^{21}$ ). Estas inmunidades permiten al abogado cumplir su obligación civil y ético-profesional de guardar confidencialidad, habilitándolo incluso para impedir el acceso de órganos jurisdiccionales o autoridades de la Administración con facultades investigativas, a las comunicaciones y productos de trabajo del abogado beneficiados por ellas. En términos muy generales, el objeto protegido por el Privilegio Cliente-Abogado conforme al derecho de los EE. UU. corresponde a (i) comunicaciones, (ii) entre un cliente y su abogado (abogado en sentido orgánico); (iii) que hayan sido y mantengan un carácter confidencial; y (iv) que hayan sido hechas en el contexto de una asesoría jurídica (intervención del abogado en sentido funcional).

Nuestra legislación procesal civil y penal recoge explícitamente una institución funcionalmente equivalente a la inmunidad del Privilegio Cliente-Abogado. La regulación general del proceso civil habilita al abogado para negarse a declarar sobre "hechos que se les hayan comunicado confidencialmente con ocasión de su (...) profesión” (Art. 360 No 1 CPC). Por su parte, la legislación procesal penal contiene una norma análoga establecida para la prueba de testigos en el contexto del juicio oral (Art. $303 \mathrm{CPP}$ ) y otras cuya finalidad es mantener la confidencialidad de la comunicación entre el cliente y su abogado en el contexto de medidas investigativas de incautación (Art. 220 CPP) e interceptación de comunicaciones (Arts. 222 y 223 CPP). Estas normas son aplicables por remisión a procedimientos especiales. Así, por ejemplo, en materia de libre competencia, las facultades investigativas de la Fiscalía Nacional Económica están limitadas por remisión a la normativa procesal penal (Art. 39 (n) Decreto Ley 211 de 1973, “DL211”) y la declaración de testigos ante el Tribunal de Defensa de la Libre Competencia se remite a la regulación procesal civil (Arts. 22 y 29 DL 211).

Por su parte, el objeto protegido por la Doctrina del Producto del Trabajo desarrollada en los EE.UU., en términos muy generales, corresponde al trabajo realizado por un abogado para su cliente (incluyendo el de los colaboradores del abogado), cuando ese tra-

\footnotetext{
19 Glenn (2007) pp. 229-231 y 242-245; Weber (1964) pp. 588-591; López (2013) pp. 503-505.

20 Epstein (2007) pp. 64-389.

21 Epstein (2007) pp. 815-962.
} 
bajo ha sido preparado para un litigio o en anticipación de un litigio inminente y siempre que no haya tenido por objeto cometer, continuar u ocultar la comisión de un delito o un acto antijurídico. Para determinar la intensidad de la protección brindada por la Doctrina del Producto del Trabajo cabe distinguir entre, por una parte, el material relevante para el litigio recopilado por el abogado (declaraciones de testigos o víctimas, copias de documentos, recopilación de datos, etc.) y, por la otra, el pensamiento del abogado en relación con el litigio. La protección al primer tipo de trabajo solo cede cuando resulta relevante para el caso de que se trate y no puede conseguirse de otra manera sin excesiva dificultad (undue hardship). En cuanto al segundo, "el pensamiento del abogado [Opinion Work Product] -teorías, análisis, impresiones mentales, opiniones, etc.- está en el corazón del sistema adversarial y la privacidad es esencial para el pensamiento del abogado; consiguientemente, la protección es máxima, sino absoluta, para materiales que revelarían esa parte del Producto del Trabajo"22.

Aunque la Doctrina del Producto del Trabajo debe entenderse incluida como parte de la garantía constitucional a defensa jurídica (Art. 19 No 3 (2) Constitución Política de la República), el derecho procesal chileno no la recoge explícitamente, probablemente porque nuestra cultura jurídica -tradicionalmente respetuosa de la privacidad del trabajo del abogado e insuficientemente sofisticada- no la ha hecho necesaria. La protección que el CPC dispensa a los documentos "secretos o confidenciales" (Art. 349 CPC) brinda la oportunidad para justificar su existencia dentro del proceso civil. La doctrina procesal tradicional no se ha ocupado en determinar en qué consiste ese concepto de "documento secreto o confidencial"23. Los principales repertorios o estudios de jurisprudencia del CPC tampoco dan cuenta de ningún fallo que trate el punto ${ }^{24}$. La falta de tratamiento dogmático del "documento secreto o confidencial" contenido en el Art. 349 CPC hace urgente un desarrollo conceptual del mismo desde la perspectiva de los distintos regímenes de secreto vigentes en Chile, incluyendo la Doctrina del Producto del Trabajo. Por su parte, en materia procesal penal, se ha sugerido que el Art. 220 CPP constituye un reconocimiento legal de la Doctrina del Producto del Trabajo ${ }^{25}$. Esta tesis parece equivocada ya que todos los casos incluidos en el Art. 220 CPP se refieren a comunicaciones o derivados de estas y, como tales, están cubiertas por el Privilegio Cliente-Abogado. En efecto, la circunstancia que los casos señalados estén calificados en función del Art. 303 CPP los acota al "secreto que se les hubiere confiado", vale decir, a comunicaciones. Adicionalmente, en el derecho comparado, la Doctrina del Producto del Trabajo solo provee cobertura al trabajo del abogado preparado para o en anticipación inminente de un litigio ${ }^{26}$. El Art. 220 CPP no contiene tal exigencia.

A diferencia del Deber de Confidencialidad, el Secreto Profesional no es parte de una relación jurídica de derecho privado, sino que de derecho público. Esta relación se

\footnotetext{
22 Epstein (2007) p. 795, resumiendo el stare decisis de HICKMAN V. TAYLOR (1947) en esta área.

23 Ver Rodríguez (2005) pp. 135-136; Paillas (2002) pp. 66 y ss; Maturana (2003) pp. 15-17.

24 Ver Repertorio de Legislación y Jurisprudencia Chilena. Código de Procedimiento Civil, Jurídica, Santiago, 2010, T. II, pp. 139 y 140; Código de Procedimiento Civil anotado, concordado y con jurisprudencia, Jurídica, Santiago, 2010, p. 290; y Rioseco (2016) pp. 365-383.

25 BASCUÑan (2011) p. 257.

26 Epstein (2007) pp. 824-913.
} 
estructura sobre el circuito potestad-carga-inmunidad ${ }^{27}$. Su punto de partida es la potestad, la que se caracteriza por habilitar a su titular (típicamente, una autoridad estatal) para alterar unilateralmente la situación jurídica de sus destinatarios (por ejemplo, los administrados), poniéndolos en la necesidad de hacer alguna cosa (por ejemplo, entregar un documento, declarar en una audiencia, etc.), o sea, imponerles una carga ${ }^{28}$. El circuito se completa con la categoría jurídica de inmunidad, que exime de la carga a algunos de sus destinatarios. El Secreto Profesional es una inmunidad que exime a los abogados de la carga de entregar información obtenida o producida en el desempeño de la abogacía a una autoridad que la requiere.

Las inmunidades habilitan a ciertos administrados comprendidos dentro del ámbito de aplicación de una potestad para eximirse de cumplir con la carga que el Estado busca imponerles. De esta forma, las inmunidades son exenciones a la carga pública, no delimitaciones de su ámbito de aplicación. Mientras que los criterios bajo los cuales se determinan los límites de una carga pública afectan a todos los administrados por igual, las inmunidades solo benefician a algunos de ellos. De esto se sigue que límites e inmunidades están sujetos a criterios interpretativos distintos. En efecto, la naturaleza excepcional del Secreto Profesional en tanto inmunidad la hace una institución que debe ser objeto de interpretación estricta: solo existen las inmunidades establecidas por la ley, estando vedada al intérprete la creación de inmunidades a partir de razonamientos analógicos.

Una consecuencia relevante de constituir el Secreto Profesional una manifestación del Deber de Confidencialidad es que no está establecido en favor del abogado. El Secreto Profesional es una forma de proteger la confidencialidad que el abogado debe a su cliente. Por esta razón, resulta criticable que el Código de Ética del Colegio de Abogados de Chile de 1948 ("CEP 1948") se haya referido a esta inmunidad como "un deber y un derecho del abogado" (Art. 10). Por lo mismo, el profesional siempre debe hacer valer el Secreto Profesional si se ve requerido a revelar información plausiblemente cubierta por este, como adecuadamente reconoce el Art. 60 del CEP 2011. Solamente el cliente puede relevar al abogado de este deber, por la vía de renunciar (Art. 12 CC) al derecho correlativo al Deber de Confidencialidad que subyace al Secreto Profesional.

\section{JUSTIFICACIONES DEL SECRETO PROFESIONAL}

El Secreto Profesional importa siempre el sacrificio de potestades públicas (investigativas o jurisdiccionales) que sirven a un fin valioso y, además, entraña per se una tensión con el principio de igualdad ante la ley y las cargas públicas. En la medida que genera tales problemas, el Secreto Profesional debe estar justificado por un interés adicional (a la mera expectativa de reserva, vinculada con el carácter fiduciario y, con alguna frecuencia, pudoroso de la encomienda profesional) que compense el déficit valorativo resultante de habilitar a sujetos determinados para negar al Estado acceso a información relevante para cumplir un interés público. De ello resulta que el Secreto Profesional tenga un ámbito de

\footnotetext{
27 Usando la terminología de Hohfeld (1913) pp. 44-57.

28 Ver Hohfeld (1913) pp. 44-53.
} 
protección más restringido que el Deber de Confidencialidad. El Secreto Profesional solo ampara una parte limitada de la información cubierta por el Deber de Confidencialidad, aquélla en la que concurren elementos adicionales a la fiducia que, conforme se señaló en la sección III precedente, justifica ese deber. La presencia de estas justificaciones adicionales determina no solo la procedencia del Secreto Profesional, sino también su extensión. Según se describe a continuación, estas se identifican con (i) facilitar el cumplimiento espontáneo del Derecho por el cliente (ii) hacer efectiva la autonomía que el sistema jurídico reconoce a la persona del cliente y (iii) el respeto de ciertos derechos fundamentales.

La primera de estas razones adicionales surge del obvio interés público asociado al cumplimiento del Derecho por parte de los miembros de una comunidad política, sin el cual, no hay sociedad posible; no, al menos, en los estándares que disfrutamos. Por una cuestión práctica, solo es posible forzar el cumplimiento del Derecho respecto de un número marginal de casos de desviación: ningún Estado es capaz de crear y mantener una fuerza de policía suficientemente grande y poderosa como para ejercer coerción efectiva en forma simultánea sobre toda (o una parte significativa de) la comunidad política. Por ello, la efectividad de un ordenamiento jurídico depende críticamente de que este sea seguido por la mayoría de los sujetos, en la mayoría de los casos, en forma espontánea, esto es, no por efecto del uso o amenaza inminente del uso de la fuerza ${ }^{29}$.

Para lograr ese cumplimiento espontáneo, la creciente formalización, abstracción y autonomía conceptual de las instituciones jurídicas de las sociedades modernas ${ }^{30}$ ha requerido el desarrollo de una clase de expertos (los abogados) que asesoren a los sujetos en cómo interactuar con las fórmulas generales del Derecho ${ }^{31}$. Esto es especialmente evidente respecto de los denominados "casos difíciles", en los cuales es complejo determinar cómo los trata el Derecho. De esta forma, en la práctica, el abogado es quien informa a su cliente sobre cómo se vincula la regulación jurídica creada por el Estado con la situación particular en la que se encuentra (actual o prospectivamente) el cliente y por la cual ha consultado al abogado. En consecuencia, el rol del abogado es crítico para que los miembros de una comunidad política moderna puedan cumplir los casos difíciles del Derecho en forma espontánea.

Para que los abogados puedan desarrollar ese rol es necesario, primero, que sean consultados por sus clientes y, segundo, que conozcan todos los hechos cuya calificación jurídica es objeto de la consulta. De lo contrario, el abogado o no sería convocado a cumplir su rol asesor o no estaría en condiciones de cumplirlo, con el consiguiente fracaso en su función mediadora entre el cliente y el Derecho, y con la gravísima consecuencia -para la convivencia civilizada- de que el Derecho no sea cumplido espontáneamente. La promoción del cumplimiento espontáneo del Derecho requiere, entonces, generar las condiciones para facilitar la consulta al abogado, así como un flujo fluido y completo de la información fáctica relevante desde el cliente al abogado. El Deber de Confidencialidad y el Secreto Profesional cumplen con esa función por la vía, el primero, de generar una intensa ${ }^{32}$ obligación

\footnotetext{
29 Hart (1961) p. 61; Fuller (1958) p. 642.

30 Ver concepto de "derecho autónomo" en Nonet y Selznick (2001) pp. 53-72.

31 Cotterell (1992) pp. 179-180.

32 Intensa, en tanto su infracción acarrea la imposición de sanciones penales y/o ético-profesionales.
} 
para el abogado de confidencialidad respecto de toda la información que reciba del cliente (u obtenga o desarrolle a partir de ella), incluyendo el hecho de la consulta y, el segundo, de resguardar el núcleo de esa información respecto del requerimiento de información por parte del Estado. El objetivo final de esas instituciones, desde esta primera perspectiva de análisis, es dar acceso al abogado a todos los aspectos de hecho del caso que son relevantes para su calificación jurídica, poniendo así al abogado en situación de brindar consejo a su cliente (esto es, informarle cómo trata el Derecho la conducta consultada) y, de esta forma, hacer posible el cumplimiento espontáneo del Derecho por el cliente ${ }^{33}$.

A esta justificación de interés público se suma otra cuyo centro de gravedad es, en última instancia, privado. Siguiendo la tradición liberal ${ }^{34}$, atendido que la dignidad de la persona humana arranca de su condición de ser autónomo, constituye requisito necesario, aunque no suficiente, para que una sociedad pueda ser considerada justa, que el derecho que la regula efectivamente reconozca amplias esferas de autonomía ("espacio moral") 35 para cada uno de sus miembros. En sociedades cuyas regulaciones han alcanzado altos niveles de formalidad y complejidad, como la nuestra, tal reconocimiento solo será efectivo cuando cualquiera de sus miembros pueda acceder a expertos (abogados) que le informen si la conducta concreta que se propone realizar se encuentra o no dentro del rango de autonomía que el sistema jurídico le reconoce ${ }^{36}$. Para que el abogado pueda desempeñar idóneamente esa función informativa necesita hacerse de los hechos del caso prospectivo del cliente. Por las mismas razones entregadas a propósito de la justificación pública de la abogacía descrita en el párrafo precedente, el Deber de Confidencialidad y el Secreto Profesional crean las condiciones para que se produzca un flujo fluido de información fáctica desde el cliente al abogado.

Los argumentos anteriores operan respecto de la función asesora de la abogacía. Respecto de la abogacía de litigación, razones adicionales justifican el Deber de Confidencialidad, ahora desde la perspectiva del respeto a los derechos fundamentales. Todas ellas se suscitan en el contexto de un proceso judicial o administrativo y van "desde el argumento de principio que ve en el secreto del abogado defensor penal una proyección del Derecho fundamental de su cliente a la no auto-inculpación ${ }^{37}$ [...a] la extendida justificación del privilegio como un presupuesto del debido proceso, ya sea que lo afirme como Derecho in-

\footnotetext{
33 Epstein (2007) pp. 4-8; Grupo de trabajo sobre secreto profesional, Comisión de Ética, Colegio de Abogados de Chile A.G. (2008) p. 9.

${ }^{34}$ Murphy y Coleman la denominan "Kantianismo", en tanto consideran que es Kant quien mejor plantea esa tradición; agregan que, usualmente, se le conoce como la tradición de los "derechos naturales", pero que sería mejor llamarla tradición "liberal". Finalmente, hacen referencia a "que es esta tradición general (no Kant propiamente tal) quien ha ejercido poderosas influencias en el Derecho Constitucional Estadounidense”, tradición generalmente asociada con John Locke y Tomás Jefferson en ese país. Murphy y Coleman (1990) pp. 71, 77, 78 y 99.

35 Nozick (1974) p. 57.

36 Fried (1976) pp. 1073-1075.

37 Esto es, un derecho de rango constitucional (Art. 19 No 7 (f)), Constitución República de Chile.
} 
dividual, en el sentido de una garantía institucional de la autonomía de la persona, o como interés colectivo, en el sentido de una regla constitutiva del sistema adversativo" ${ }^{38}$.

De esta forma, el Privilegio Cliente-Abogado encuentra su justificación, principalmente, en el argumento de interés público en el cumplimiento espontáneo del Derecho (en tanto exigencia de eficiencia) y de reconocimiento efectivo por el Estado de esferas de autonomía de sus regulados (como exigencia de justicia). En algunos escenarios concurrirán, además, las justificaciones procesales indicadas en el párrafo precedente. En cambio, la Doctrina del Producto del Trabajo encuentra su razón en dichas justificaciones procesales, especialmente la referida al "debido proceso", en tanto el carácter confidencial de la labor del abogado para promover los intereses legítimos de su cliente en un litigio forma parte estructural del sistema adversativo ${ }^{39}$. Forzar al abogado a revelar su trabajo en preparación de un litigio equivale a negar el principio de bilateralidad de la audiencia. La principal consecuencia de esta diferente justificación de ambas instituciones es su ámbito de competencia: el Privilegio dice relación tanto con el rol del abogado como instrumento de acceso al Derecho (rol asesor) como a la jurisdicción (rol judicial); mientras que la Doctrina, justificada en argumentos procesales, se circunscribe al segundo de esos roles.

Existen razones poderosas para divulgar información sujeta al Deber de Confidencialidad distintas a colaborar en la labor jurisdiccional o investigativa del Estado. La más relevante de ellas es la divulgación de información que permite evitar la comisión o consumación de un crimen o un simple delito, o un serio peligro de muerte o daño corporal a una o más personas. Como es obvio, es perfectamente posible que, en esos casos, el Deber de Confidencialidad se encuentre, a su vez, respaldado por una o más de las justificaciones adicionales a su naturaleza fiduciaria descritas precedentemente en esta sección V. Lo anterior suscita un dilema mayor, a saber: optar por las justificaciones adicionales a la fiducia que sostienen el Deber de Confidencialidad (i.e., justicia y eficacia del sistema jurídico, debido proceso), sacrificando la prevención del delito o la evitación de muertes y daños corporales; o, a la inversa, sacrificar esas muy relevantes justificaciones en aras de evitar delitos, muertes y daños físicos. Por no haber requerimiento estatal de información en estos escenarios, el dilema no se resuelve en el nivel de referencia procesal legal, sino en el ético profesional, que faculta al abogado a revelar información sujeta a confidencialidad sin el consentimiento del cliente (salvo en el caso de evitación de crímenes, en que el abogado debe revelar), pero sujeta cualquiera de esas revelaciones a estrictos estándares de necesidad y proporcionalidad ${ }^{40}$. Se trata, así, de una solución que no opta en forma binaria por uno

\footnotetext{
38 Grupo de trabajo sobre secreto profesional, Comisión de Ética, Colegio de Abogados de Chile A.G. (2008) p. 10.

39 "Un abogado, como oficial de la corte, está obligado a trabajar para el cumplimiento del Derecho, al mismo tiempo de fielmente proteger los legítimos intereses de su cliente. En el ejercicio de sus deberes, es esencial que el abogado trabaje con cierto grado de privacidad, libre de innecesarias intrusiones de las contrapartes y sus abogados. La adecuada preparación del caso de un cliente exige que el abogado reúna información, separe lo que considere relevante de lo irrelevante, prepare teorías legales, y planifique una estrategia sin indebida e innecesaria interferencia. Esa es la manera histórica y necesaria en la que los abogados han actuado dentro del marco de nuestro sistema jurídico para la promoción del Derecho y la protección de los intereses de sus clientes" (La traducción es nuestra) HICKMAN VS. TAYLOR (1947).

40 Arts. 53 a 58 CEP 2011.
} 
de los grupos de intereses en pugna, sino que busca un equilibrio (y, en buena medida, deja la sintonía fina del mismo en manos del abogado, en tanto, salvo para la evitación de crímenes, lo autoriza sin forzarlo a divulgar). La solución descrita se asemeja, mutatis mutandis, a la alcanzada en el escenario del Secreto Profesional, en que el Deber de Confidencialidad prevalece exclusivamente cuando se encuentra justificado por criterios adicionales a la fiducia.

\section{SITUACIÓN DEL SECRETO PROFESIONAL DEL ABOGADO EN DOCTRINA Y JURISPRUDENCIA NACIONAL}

Durante los últimos 50 años la doctrina chilena prácticamente no se ha ocupado del Secreto Profesional. Las únicas excepciones a ello de que tenemos noticias son el trabajo de Antonio Bascuñán R., que lo analiza tangencialmente, a propósito de la regulación formulada por el CEP 2011 a la vecina institución del Deber de Confidencialidad y un trabajo de Mario Correa cuyo centro de gravedad también es esa regulación del CEP 2011 $1^{41}$. Las obras anteriores a ese período, no obstante su denominación, también se refieren al Deber de Confidencialidad ${ }^{42}$.

Por su parte, la invocación del Secreto Profesional por abogados expuestos a la incautación judicial de documentos que contienen información sobre su cliente o citados a declarar como testigos en juicio, ha llevado a nuestros tribunales para, todavía de manera incipiente, iniciar un desarrollo dogmático de esta institución. Los rasgos más salientes de esa jurisprudencia son los siguientes:

(1) El Secreto Profesional formaría parte de la garantía constitucional a un debido proceso, vinculado específicamente al derecho de toda persona a contar con defensa jurídica ${ }^{43}$;

(2) El contenido básico de esa institución consiste en habilitar al abogado para excusarse de proveer cierta información que ha conocido en su desempeño profesional frente a una petición al efecto de alguna institución estatal, paradigmáticamente, de los Tribunales de Justicia ${ }^{44} ; \mathrm{y}$

(3) Finalmente, la jurisprudencia asigna una naturaleza excepcional al Secreto Profesional $^{45}$, la que hace operativa por la vía de acotar la protección que brinda esta institución a confidencias conocidas por el abogado con ocasión de la profesión ${ }^{46}$.

41 BASCUÑ́Án (2011) pp. 221-263; CoRrea (2013) pp. 255-268.

42 Novoa Monreal (1944) pp. 85-100; De la Carrera (1963) y Montes (1963). La obra de Novoa Monreal va aún más allá y excluye expresamente de su análisis la regulación a la sazón vigente del Secreto Profesional, ver, p. 85.

43 Consejo para la TRansparencia (2012), considerando 20; Consejo de Defensa del Estado (2012b), considerando $19^{\circ}$; y CONSEJO DE DefENSA DEl EsTADo (2012a), considerando $20^{\circ}$.

44 Considerandos $23^{\circ}$; $24^{\circ}$; y $24^{\circ}$ de los fallos citados en pie anterior, en el mismo orden.

45 Vicaría de la SOLIDARIDAd CON FisCAL CEA (1989). En GUtTMAn CON GUTtMAn (1953), el caso quizás más emblemático sobre la materia, la Corte de Apelaciones de Santiago argumentó en el mismo sentido. Ver considerandos $\left.3^{\circ}, 6^{\circ} \mathrm{c}\right), 6$ e) y $7^{\circ}$. C. Santiago, 18 de diciembre de 1953.

46 Guttman con Guttman (1953), Considerando 5², p. 129. 
El desarrollo conceptual del Secreto Profesional por nuestros tribunales, aunque valioso, es insuficiente. En particular, nuestra jurisprudencia ha cometido el error de identificar el Secreto Profesional con el Deber de Confidencialidad. En los fallos recién citados del año 2012, la Corte Suprema (i) afirmó "[q]ue el secreto profesional constituye una obligación legal que tiene como sujeto pasivo a un profesional y que importa que el mismo no puede revelar lo que el cliente mantiene oculto y solamente ha permitido conocer al profesional para el mejor desempeño de su profesión”, una caracterización precisa, no del Secreto Profesional sino del Deber de Confidencialidad; (ii) resolvió requerimientos de información efectuados por el Consejo de Transparencia al Consejo de Defensa del Estado -un escenario de Secreto Profesional- aplicando regulación sobre Deber de Confidencialidad y (iii) peor aún, identificó erradamente esa regulación ${ }^{47}$. En el lado positivo, estos fallos de la Corte Suprema terminaron con la tesis a la sazón seguida por el Colegio de Abogados de Chile A.G., según la cual existía un estatuto ético profesional diferenciado dependiendo si el abogado se encontraba o no afiliado a esa organización gremial ${ }^{48}$.

En síntesis, la Corte Suprema trata al Secreto Profesional como sinónimo del Deber de Confidencialidad y le (mal) aplica la regulación incluida en el CEP 2011 para esa última institución. Esto último constituye una inconsistencia, considerando que ese cuerpo normativo se basa precisamente en "(...) la distinción conceptual entre el deber ético de confidencialidad y el derecho legal al secreto profesional” ${ }^{49}$. Finalmente, identificar ambas instituciones lleva a nuestros tribunales a considerar como condiciones de aplicación del segundo las condiciones de aplicación del primero. Lo anterior impide que los tribunales se hagan de información relevante para la correcta decisión del caso y conocida por los abogados, en escenarios en que el Secreto Profesional no está justificado, infligiendo, al hacerlo, un daño grave a bienes jurídicos tan preciados como el principio de igualdad ante las cargas públicas y el acceso por los tribunales a los hechos del caso sometido a su jurisdicción.

Pudiera pensarse que lo afirmado en este trabajo reduce en exceso el ámbito de aplicación del Secreto Profesional respecto del reconocimiento tradicional de esa institución en nuestro país. No hay tal reducción. En efecto, nuestros tribunales han considerado consistentemente el Secreto Profesional como una institución excepcional cuya cobertura se limita a lo que se le haya "comunicado confidencialmente" al abogado "con ocasión de su profesión”. Basta comparar esos requisitos de procedencia con los que hemos planteado precedentemente en base a la tradición del privilegio en los Estados Unidos, para advertir su coincidencia conceptual. En consecuencia, lejos de atrofiar la aplicación del Secreto Profesional en Chile, al distinguirlo del Deber de Confidencialidad, la tesis aquí propuesta permite que este último expanda su ámbito de aplicación respecto de su entendimiento tradicional, en línea con lo buscado por el CEP 2011. No es que el Secreto Profesional se reduzca. Es el Deber de Confidencial el que crece.

\footnotetext{
47 En opinión de los autores, la regulación ética actualmente vigente en Chile para los abogados, tanto colegiados como no colegiados, es el CEP 1948 según ese código se encontraba vigente en febrero de 1981. La justificación dogmática de esta afirmación se encuentra en ANRíQuez (2016).

48 BASCuñán (2011) p. 226, en nota al pie; Anríquez (2016) pp. 358-359.

49 BASCUÑán (2011) p. 226.
} 


\section{CONCLUSIONES}

El desarrollo de una dogmática del Secreto Profesional en Chile debe partir por distinguir dicha institución del Deber de Confidencialidad. Este último abarca toda la información sobre el cliente y el asunto objeto de consulta que el abogado ha conocido en su desempeño profesional. Esto obedece a que el Deber de Confidencialidad constituye siempre una manifestación de la confianza intrínseca a la relación profesional cliente-abogado (justificación fiduciaria). Dependiendo del escenario, el Deber de Confidencialidad puede resultar, además, justificado por una o más de las siguientes razones: En un escenario típicamente de asesoría, se justifica porque mejora la posibilidad de que el abogado acceda a información de hecho necesaria para asesorar al cliente en cómo cumplir espontáneamente el Derecho y/o hacer valer la esfera de autonomía que el sistema jurídico le reconoce (justificaciones consecuencialistas). En el escenario judicial, el Deber de Confidencialidad se justifica en tanto forma parte esencial de la garantía constitucional a un debido proceso y defensa jurídica (justificación asociada al debido proceso).

En cambio, el Secreto Profesional es una inmunidad que hace operativo el Deber de Confidencialidad cuando el Estado requiere al abogado información en el contexto de un proceso jurisdiccional o administrativo. Por lo tanto, el Deber de Confidencialidad es un presupuesto del Secreto Profesional. Una consecuencia de ello es que si el Deber de Confidencialidad cesa por cualquier causa, por ejemplo, por renuncia del cliente al derecho correlativo, el abogado pierde la facultad de excusarse de proveer la información requerida por la vía de invocar el Secreto Profesional. Otra consecuencia es que el Secreto Profesional, a diferencia del Deber de Confidencialidad, está sujeto a una regla de interpretación estricta.

El Secreto Profesional implica per se un menoscabo (i) del principio de igualdad ante la ley y las cargas públicas y (ii) de la facultad del Estado para acceder a información de hecho relevante para resolver controversias jurídicas o investigar y sancionar conductas ilícitas. La mayor importancia relativa de estos bienes jurídicos trae como consecuencia que el Deber de Confidencialidad sea derrotado por ellos cuando se sustenta exclusivamente en su justificación fiduciaria. Sin embargo, cuando el Deber de Confidencialidad descansa en cualquiera de las justificaciones consecuencialistas o en el resguardo del debido proceso, la ley ha resuelto ex ante su enfrentamiento con el requerimiento de información judicial o investigativo en favor del Deber de Confidencialidad. De ello resulta que el Secreto Profesional protege solo una parte de la información cubierta por el Deber de Confidencialidad: aquélla a la que resultan aplicables esas justificaciones adicionales. Esto también explica el carácter de derecho estricto del Secreto Profesional.

Las justificaciones del Secreto Profesional permiten identificar una serie de criterios interpretativos relevantes para la reconstrucción dogmática de esta institución, incluyendo que (i) la protección del Secreto Profesional dice solo relación con, por una parte, las comunicaciones entre cliente y abogado con objeto de asesoría jurídica y, por la otra, el trabajo producido por el segundo para el primero en el contexto de un juicio (actual o inminente), pero no alcanza los hechos mismos, los que pueden ser acreditados en juicio por

cualquier vía alternativa; (ii) la información beneficiada con la inmunidad del Secreto Profesional debe ser protegida en términos equivalentes, cualquiera sea la vía de acceso a ella 
(por ejemplo, declaración testimonial, incautación, interceptación); y (iii) sin perjuicio del deber ético profesional del abogado de invocar la regulación del Secreto Profesional en caso de ser requerido por autoridad a divulgar información sujeta al Deber de Confidencialidad, el Secreto Profesional no puede ser declarado de oficio por el tribunal, sino que tiene que ser alegado por el abogado que lo invoca y, en caso de disputa, justificado por este ${ }^{50}$.

\section{BIBLIOGRAFÍA CITADA}

Anríquez NovoA, Álvaro (2016): "Ética Profesional del Abogado: Normativa Vigente en Chile”, Revista Ius et Praxis, año 22, No 2: pp. 331-372.

Barros Bourie, Enrique (2006): Tratado de la Responsabilidad Extracontractual (Santiago, Editorial Jurídica de Chile).

Bascuñán Rodríguez, Antonio (2011): "Deber de Confidencialidad y Secreto Profesional del Abogado", Revista de Estudios de la Justicia, núm. 15: pp. 221-263.

Blumberg, Abraham S. (1967): "The Practice of Law as Confidence Game: Organizational Cooptation of a Profession”, Law and Society Review, vol. 1, núm. 2: pp. 15-40.

Correa Bascuñán, Mario (2013): "El secreto profesional del abogado en el nuevo Código de Ética", en Contreras, Sebastián y Miranda, Alejandro (edits.), Cuadernos de Extensión Jurídica (U. de los Andes): Ética profesional del abogado, Principios generales y comentarios al nuevo Código de Ética Profesional del Colegio de Abogados de Chile, No 24 (Santiago, Universidad de Los Andes) pp. 255-268.

CotTerell, Roger (1992): The Sociology of Law. An Introduction (Oxford y Nueva York, Oxford University Press, segunda edición).

De la Carrera Bascuñán, Helena (1963): El Secreto Profesional del Abogado (Estudio teórico $y$ práctico) (Santiago, Editorial Jurídica).

De la Maza, Iñigo (2002): "Los Abogados en Chile: desde el Estado al mercado", Colección Informes de Investigación, Centro de Investigaciones Jurídicas, Facultad de Derecho, Universidad Diego Portales, No 10, año 4, enero 2002: pp. 191-216.

Epstein, Edna Selan (2007): The Attorney-Client Privilege and the Work-Product Doctrine (Chicago, American Bar Association, quinta edición).

Fried, Charles (1976), "The Lawyer as Friend: The Moral Foundations of the LawyerClient Relation", 85 Yale L.J. 1060: pp. 1073-1075.

Fuller, Lon L. (1958): "Positivism and Fidelity to Law: A Reply to Professor Hart”, Harvard Law Review, vol. 71, núm. 4: pp. 630-672.

Glenn, H. Patrick (2007): Legal Traditions of the World (Oxford y Nueva York, Oxford University Press, tercera edición).

\footnotetext{
50 Los sentidos aparentemente opuestos entre, por una parte, la conducta requerida al abogado por la regulación ético-profesional del Deber de Confidencialidad; y, por la otra, la requerida al juez, por la regulación procesal en el nivel de referencia legal, obedecen a una lógica de distribución y complementación de roles entre esas funciones y, también por esa vía, de solución de compromiso de los múltiples y relevantes bienes jurídicos en tensión.
} 
Grupo de trabajo sobre secreto profesional, Comisión de Ética, Colegio de Abogados De Chile A.G. (2008): Propuesta de Nueva Regulación Ética del Colegio de Abogados relativa al Deber de Confidencialidad y Secreto Profesional (Santiago, inédito).

Hohfeld, Wesley Newcomb (1913): "Some Fundamental Legal Conceptions as Applied in Judicial Reasoning”, The Yale Law Journal, vol. 23, núm. 1: pp. 16-59.

Hart, Herbert Lionel A. (1961): The Concept of Law (Oxford y Nueva York Oxford University Press, reimpresión de 1994).

López Masle, Julián (2013): "La defensa del 'culpable' en la ética del profesional defensor", en Grez, Pablo, Wilenmann, Javier y Fuenzalida, Pablo (coord.), Una vida en la Universidad de Chile. Celebrando al profesor Antonio Bascuñán Valdés (Santiago, Legal Publishing) pp. 497-537.

Maturana Miquel, Cristián (2003): Los Medios de Prueba (separata rústica) (Santiago Departamento de Derecho Procesal, Facultad de Derecho, Universidad de Chile).

Montes Olavarrieta, Leonidas (1963): De la Prevaricación de Abogados y Procuradores (Santiago, Editorial Jurídica).

Murphy, Jeffrie y Coleman, Jules (1990): Philosophy of Law, An Introduction to Jurisprudence (Boulder, San Francisco y Londres, Westview Press, edición revisada).

Nonet, Philippe, y Selznick, Philip (2001): Law \& Society in Transition. Towards responsive law (New Brunswick y Londres, Transaction Publishers, segunda edición).

Novoa Monreal, Eduardo (1944): "La Obligación Jurídica de Secreto Profesional", en Revista de Derecho, Jurisprudencia y Ciencias Sociales, T. XLI, No 1 y 2, marzo y abril 1944: pp. 85-100.

Nozick, Robert (1974): Anarchy, State and Utopia (Nueva York, Basic Books).

Paillas Peña, Enrique (2002): Estudios de Derecho Probatorio (Santiago, Editorial Jurídica).

Posner, Richard (1944): Overcoming Law (Cambridge, Harvard University Press).

Repertorio de Legislación y Jurisprudencia Chilena. Código de Procedimiento Civil, Tomo II (2010): (Santiago, Editorial Jurídica).

Rioseco Enríquez, Emilio (2016): La Prueba Ante la Jurisprudencia. Derecho civil y procesal civil, Tomo I (Santiago, Editorial Jurídica)

Rodríguez Papic, Ignacio (2005): Procedimiento Civil. Juicio ordinario de mayor cuantía (Santiago, Editorial Jurídica, séptima edición).

Squella Narducci, Agustín (2001): Filosofía del Derecho (Santiago, Editorial Jurídica, primera edición).

Weber, Max (1964): Economía y Sociedad (México D.F., Fondo de Cultura Económica) (reimpresión de 2005).

\section{NORMAS JURÍDICAS CITADAS}

Alemania, Zivilprozessordnung (ZPO), Reichsgesetzblatt, 30 de enero de 1877 y republicada en Bundesgesetzblatt, 5 de diciembre de 2005.

Alemania, Bundesrechtsanwaltsordnung, Bundesgesetzblatt, 1 de agosto de 1959.

Alemania, Strafprozessordnung (StPO), Reichsgesetzblatt, 1 de febrero de 1877 y republicada en Bundesgesetzblatt, 7 de abril de 1987. 
Chile, Constitución Política de la República, Diario Oficial, 22 de septiembre de 2005.

Chile, Código Orgánico de Tribunales, Diario Oficial, 9 de julio de 1943.

Chile, Código de Procedimiento Civil, Diario Oficial, 30 de agosto de 1902.

Chile, Código Civil, Diario Oficial, 30 de mayo de 2000.

Chile, Código Penal, Diario Oficial, 12 de noviembre de 1874.

Chile, Código Procesal Penal, Diario Oficial, 12 de octubre de 2000.

Chile, Decreto Ley 211 del Ministerio de Economía, Fomento y Reconstrucción de 1973, Fija Normas para la Defensa de la Libre Competencia, Diario Oficial, 22 de diciembre de 1973.

Chile, Decreto Ley 3621 del Ministerio de Justicia de 1981, Diario Oficial, 7 de febrero de 1981.

Chile, Código de Ética del Colegio de Abogados de Chile, 1948.

Chile, Código de Ética del Colegio de Abogados de Chile A.G., agosto 2011.

Francia, Code de Procédure Pénale français, 2 de marzo de 1959.

\section{JURISPRUDENCIA CITADA}

BERD V LOVELACE [1577] Cary 62).

Consejo de Defensa del Estado (2012a), Corte Suprema, Rol 2582-2012, 28 de noviembre de 2012 (recurso de queja). Disponible en: https://oficinajudicialvirtual.pjud.cl/ home/index.php Fecha de consulta: 5 de agosto de 2020.

Consejo de Defensa del Estado (2012b), Corte Suprema, Rol 2788-2012, 28 de noviembre de 2012 (recurso de queja). Disponible en: https://oficinajudicialvirtual.pjud.cl/ home/index.php Fecha de consulta: 5 de agosto de 2020.

Consejo para la Transparencia (2012), Corte Suprema, Rol 2423-2012, 28 de noviembre de 2012 (recurso de queja). Disponible en: https://oficinajudicialvirtual.pjud.cl/home/ index.php Fecha de consulta: 5 de agosto de 2020.

HICKMAN VS. TAYLOR 329 U.S. 495 (1947)

Guttman con Guttman (1953). Corte de Apelaciones de Santiago, 18 de diciembre de 1953 (recurso de queja), Revista de Derecho y Jurisprudencia, Tomo 51 (1954), 2a parte, Sección Primera, pp. 129 y 130.

Vicaría de la Solidaridad con Fiscal CEA (1989), Corte Suprema, 31 de enero de 1989 (queja disciplinaria), Fallos del Mes, núm. 362, enero 1989, pp. 956 y ss. 